\title{
Orientation of medical undergraduates to community nutrition
}

\author{
Lopamudra $^{1}$, Amol R Dongre ${ }^{2}$
}

\begin{abstract}
The prevalence of non-communicable diseases is increasing and diet is an important risk factor for it. This is less recognized in the medical curriculum and even though it is there, it is presented unsystematically.

Objective: We studied theresponse to an 'innovative method of teaching nutrition' to the undergraduates and assessed their perspective of the facilitating and hindering elements.

Methodology: The nutrition model was applied to semester iv students at our institute. A session planning guide was drawn initially and short group interactive sessions were given including briefing, demonstrations and field visits followed by diet calculation and inference about the consumption of the concerned family. Feedback was taken from students and analysis was performed.
\end{abstract}

Results: The majority of the responses were, learning the basics of Interviewing (72\%), problem based assessment of Balanced diet (53\%), social determinants of nutritional diseases $(60 \%)$. The facilitating points stated were development of interviewing skills, community orientation, reasoning abilities, planning balanced diet for one-self etc. and still more of practical sessions were suggested to be included in the guide.

Conclusion: Our method of teaching nutrition was well accepted by students. They understood the key concepts and could apply them to problems based on social scenarios.

Keywords: nutrition, community orientation, undergraduates

\section{Introduction}

The epidemics of non-communicable diseases are on a rise and diet played a key risk factor (WHO, 2003). Dietary change is also advocated for the prevention and treatment of a number of major diseases (Barratt 2001). However, this is a less recognized domain in the medical curriculum. It is presented unsystematically with

\footnotetext{
${ }^{1}$ Assistant Professor,

Department of Community Medicine,

Sri ManakulaVinayagar Medical College and Hospital (SMVMCH), Pondicherry, India - 605107

${ }^{2}$ Professor, Department of Community Medicine, Sri ManakulaVinayagar Medical College and Hospital (SMVMCH), Pondicherry, India - 605107

Corresponding author:

Dr Lopamudra, Assistant Professor,

No 26, Serenite (III'floor), Rue la de Lauristan,

Opposite Sri Manakula Vinayagar Temple (Near Central

Bank), Pondicherry, India-605001
}

Email: miss.lopamudra@gmail.com little or no coordination at different levels (Forum on Food and Health, 1988). It is also evidenced (Peters 2006) that medical students and practitioners generally do not emphasize the importance of prudent dietary intake and active lifestyle in reducing the incidence and severity of chronic diseases. There is a lack of knowledge in both preventive and curative aspects of nutrition amongst medical students and is also perceived as less important than other specialties. Thus, there is a need to stress on teaching nutrition so that the students have orientation to community needs and are able to apply this in future practice.

\section{Methodology}

\section{Study setting}

The study was undertaken in the Department of Community Medicine of Sri Manakula Vinayagar Medical College and Hospital. Presently, we are making an effort to design our curriculum orientated to community needs. We had noted that even though, 'nutrition' is an important part of curriculum, medical 
undergraduates find it difficult to relate the diet history in clinic social case settings. They lacked the knowledge when they encounter if do not know how to manage the clinical cases. As medical interns, there was hardly any focus on diet based prevention modalities in patient care.

\section{Objective}

We planned to develop a systematic method of teaching nutrition so that students internalize its essentiality and apply it in clinical settings. Thus, we studied the response to an 'innovative method of teaching nutrition' to undergraduates and assessed their perspective of the facilitating and hindering elements.

\section{Procedure}

Conceptually, we divided the teaching sessions in four steps; 'Induction' (discussing the situation), Implementation' (data collection), 'Internalization' (understanding) and 'Inference' (conclusion) and applied to our students in the IV semester (4 batches, $n=127$ ) for a month. Initially, a 'Session Planning Guide' was drawn which Focused on interviewing techniques, dietary pattern, adequacy of consumption by a family, impact of socio economic status on nutritional needs, socio-cultural influence, sociology of nutritional deficits, the basics of a balanced diet and application of the concepts on key scenarios.

\section{Facilitation}

Short group interactive sessions were planned for each batch. The Induction stage included briefing about the importance of nutrition, demonstration of food pyramids, food charts, models etc. making them aware of nutrition and related problems. We shared the students' experience of cultural aspects of nutrition (e.g., hot and cold foods and other misconceptions). In implementation, a series of field visits were planned, wherein, each student was allotted one family to collect information (for 7 days) about their dietary patterns (24 hour recall method). Diet calculations were taught and inference about the consumption was made. These sessions were followed by hands on guide on importance and calculation of balanced diets. In internalization, certain key scenarios was given and were asked to identify important social elements linked to those (e.g.: Malnutrition), a brief outline of which is given below (figure 1). Problem based assessments were made with special considerations for different patho-physiological states, as well as food availability, affordability and cultural acceptability. They were stressed on preparing diet charts for vulnerable age groups and the importance of nutritional counseling. In inference, feedback was collected from students regarding the process and contents of the sessions using a five point 'likert scale' (strongly agree to strongly disagree) and a few open ended questions. The sessions were facilitated by trained social workers and were monitored and conducted by the faculty.

\section{Analysis}

Feedback was collected from all the students $(n=127)$. Analysis of the quantitative responses was performed using Epi-info (version 3.5.1) and manual content analysis was done for the open ended responses.

\section{Results}

The completed feedback forms $(n=96)$ revealed the following. Responses (majority) regarding the contents were (Table 1); learning the basics of interviewing ( $72 \%)$, problem based assessment of balanced diet $(53 \%)$, social determinants of nutritional diseases $(60 \%)$, scenario based teaching of diseases (54\%), understanding of cultural and behavioral factors $(53 \%)$, understanding the diet calculations (52\%) etc.

The major facilitating points stated were development of interviewing skills (rapport building), collecting information like diet pattern in a non-offensive way, communication skills to make the respondent open up effectively, community orientation (life style and needs), reasoning abilities (identifying the root cause), and planning a balanced diet. According to them, there was difference between their perception of the community and how it was actually. Students were unaware of how to motivate the community before but the posting helped them learn. The counseling sessions were admired for it gave the students confidence to approach patients in clinical settings.

Regarding the process, they felt that individual students' understanding was given importance. The 'interactive sessions' and the discussions were interesting. However, the students felt that still more practical sessions were required to have good community interactions. The timings of the postings were the major limitation as stated by them because most of the respondents were disturbed from their domestic work schedule. They also felt that strict facilitation of sessions by the faculty in the field settings was required because they had problems in convincing people. 
Additionally, the weather (hot summer) affected their learning in the field.

Figure 1: Principle of Application of the innovative Nutrition Teaching

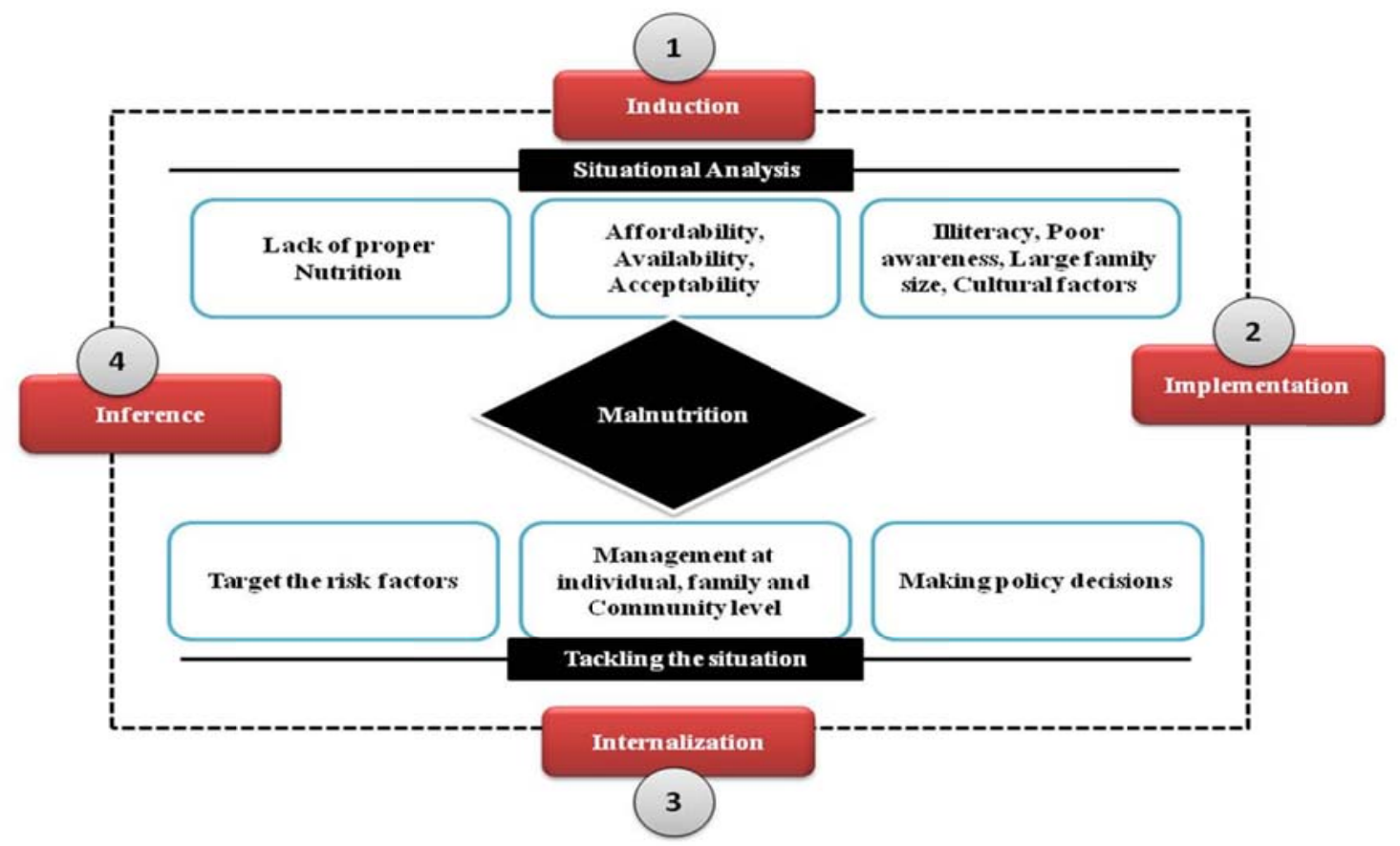

Table 1: Analysis of Student Feedback forms

\begin{tabular}{|c|c|c|c|c|c|}
\hline Feedback Responses & 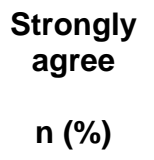 & $\begin{array}{l}\text { Agree } \\
\text { n (\%) }\end{array}$ & $\begin{array}{c}\text { Neither } \\
\text { agree nor } \\
\text { disagree } \\
\text { n (\%) }\end{array}$ & $\begin{array}{c}\text { Disagree } \\
\text { n (\%) }\end{array}$ & 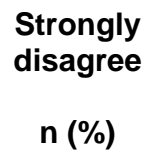 \\
\hline The sessions were enjoyable & $26(27.1)$ & $55(57.3)$ & $12(12.5)$ & $2(2.1)$ & $1(1.0)$ \\
\hline $\begin{array}{l}\text { Individual student's learning was given } \\
\text { importance }\end{array}$ & $23(24.0)$ & $49(51.0)$ & $12(12.5)$ & $11(11.5)$ & $1(1.0)$ \\
\hline $\begin{array}{l}\text { Exposure to different faculty for the events } \\
\text { was good }\end{array}$ & $21(22.1)$ & $44(46.3)$ & $19(20.0)$ & $10(10.5)$ & $1(1.1)$ \\
\hline $\begin{array}{l}\text { I could learn the basics of interviewing a } \\
\text { family }\end{array}$ & $53(55.2)$ & $40(41.7)$ & $2(2.1)$ & $1(1.0)$ & $0(0.0)$ \\
\hline $\begin{array}{l}\text { The scenario based teaching helped in } \\
\text { understanding }\end{array}$ & $28(29.2)$ & $52(54.2)$ & $13(13.5)$ & $3(3.1)$ & $0(0.0)$ \\
\hline $\begin{array}{l}\text { Able to apply the concepts of prevention in } \\
\text { a disease process }\end{array}$ & $21(21.9)$ & $57(59.4)$ & $13(13.5)$ & $4(4.2)$ & $1(1.0)$ \\
\hline Methods of diet survey are clear to me & $27(28.1)$ & $50(52.1)$ & $15(15.6)$ & $3(3.1)$ & $1(1.0)$ \\
\hline $\begin{array}{l}\text { Problem based assessment of balanced } \\
\text { diet was very useful }\end{array}$ & $37(38.9)$ & $40(42.1)$ & $12(12.6)$ & $4(4.2)$ & $2(2.1)$ \\
\hline $\begin{array}{l}\text { Importance of cultural \& behavioral factors } \\
\text { was well understood }\end{array}$ & $24(25.0)$ & $51(53.1)$ & $15(15.6)$ & $6(6.3)$ & $0(0.0)$ \\
\hline $\begin{array}{l}\text { Realized that the social problem have } \\
\text { bearing on disease }\end{array}$ & $39(40.6)$ & $48(50.0)$ & $6(6.3)$ & $3(3.1)$ & $0(0.0)$ \\
\hline $\begin{array}{l}\text { Helpful in arousing interest in assessment } \\
\text { of social needs of a family }\end{array}$ & $32(33.7)$ & $42(44.2)$ & $14(14.7)$ & $6(6.3)$ & 191.1) \\
\hline
\end{tabular}




\section{Conclusion}

We observed that teaching nutrition to the undergraduates should be interesting and should be based on real life situations. Our students could apply their knowledge on nutrition when faced with problem based solutions and could also make diet charts. We suggest that systematic teaching of nutrition from appropriate data collection with its interpretation is required. They need to be orientated to community needs and must understand socio cultural aspects of nutritional diseases. They should be able to weigh the essentiality of nutrition and its application for disease prevention as future medical professionals.

\section{References}

Barratt, J. (2001) Diet related knowledge, beliefs and actions of health professionals compared with the general population: An investigation in community trust. Journal of Human Nutrition and Dietetics, 14 (1), pp. 25-32.
Peters, E.M., Higgins-Opitz, S.B., Mclean, M. \& VanWyk, J. (2006) Enhanced dietary awareness and lifestyle changes in first-year medical students following exposure to problem-based nutrition education. SA Fam Pract, 48 (7), pp.15a-g. [Online], Available at: www.safpj.co.za/index.php/ safpj/article/download/637/557 [Accessed 20 May 2011].

Report of meeting of Forum on Food and Health, 15 May 1987: Teaching Nutrition to Medical Students. (1988) Journal of the Royal Society of Medicine, 81, pp. 176-178. [Online], Available at: http://www.ncbi.nlm. nih.gov/pmc/articles/PMC1291520/pdf/jrsocme d00164-0063.pdf [Accessed 10 July 2011].

Van Horn, L. (2006) The Nutrition Academic Am J Clin Nutr, 83 (4), pp.936S-940S. [Online], Available at: http://www.ajcn.org/ content/83/4/936S.full.pdf

World Health Organization Technical Report Series 916 (2003) Diet, Nutrition and the Prevention of Chronic Diseases: Report of a Joint WHO/FAO Expert Consultation. [Online]. Available at: whqlibdoc.who.int/ trs/who_trs_916.pdf [Accessed 10 July 2011]. 